\title{
Spider mite web mediates anti-predator behaviour
}

\author{
Felipe Lemos • Renato Almeida Sarmento • Angelo Pallini • \\ Cleide Rosa Dias • Maurice W. Sabelis • Arne Janssen
}

Received: 2 October 2009/Accepted: 9 February 2010/Published online: 27 February 2010

(C) The Author(s) 2010. This article is published with open access at Springerlink.com

\begin{abstract}
Herbivores suffer significant mortality from predation and are therefore subject to natural selection on traits promoting predator avoidance and resistance. They can employ an array of strategies to reduce predation, for example through changes in behaviour, morphology and life history. So far, the anti-predator response studied most intensively in spider mites has been the avoidance of patches with high predation risk. Less attention has been given to the dense web produced by spider mites, which is a complex structure of silken threads that is thought to hinder predators. Here, we investigate the effects of the web produced by the red spider mite, Tetranychus evansi Baker \& Pritchard, on its interactions with the predatory mite, Phytoseiulus longipes Evans. We tested whether female spider mites recognize predator cues and whether these can induce the spider mites to produce denser web. We found that the prey did not produce denser web in response to such cues, but laid more eggs suspended in the web, away from the leaf surface. These suspended eggs suffered less from predation by $P$. longipes than eggs that were laid on the leaf surface under the web. Thus, by altering their oviposition behaviour in response to predator cues, females of $T$. evansi protect their offspring.
\end{abstract}

Keywords Predation risk - Oviposition behaviour - Tetranychus evansi . Phytoseiulus longipes · Tomato · Ecosystem engineers

F. Lemos - R. A. Sarmento - A. Pallini - C. R. Dias

Department of Animal Biology, Section Entomology, Federal University of Viçosa, Viçosa, MG, Brazil

R. A. Sarmento

Department of Plant Science, Research Group: Biological Control of Pests, Federal University of Tocantins, Gurupi, TO, Brazil

R. A. Sarmento · M. W. Sabelis · A. Janssen $(\bowtie)$

IBED, Section Population Biology, University of Amsterdam, Science Park 904, 1098 XH Amsterdam, The Netherlands

e-mail: arne.janssen@uva.nl 


\section{Introduction}

Predation is one of the main factors determining the distribution and dynamics of prey populations. It has an effect on the dynamics of prey through removal of individuals. Predators can also have non-lethal effects on prey through the induction of changes in the prey (Sih 1980, 1982; Kats and Dill 1998; Lima 1998). To avoid predation, prey employ a large range of strategies, such as behavioural, morphological and life history changes (Havel 1987; Kats and Dill 1998; Tollrian and Harvell 1999; Montserrat et al. 2007; Chivers et al. 2008). However, these changes come with a cost. For example, prey may reduce time and energy spent on mating and foraging in order to hide or escape when they perceive predators (Lima 1998). Since these responses will reduce prey reproduction in one way or another, predators also exert non-lethal effects on prey, thus also affecting their distribution and dynamics.

The first step in predator-induced changes in prey is the recognition of cues associated with predation risk. Prey are known to use auditory, visual and chemical senses to perceive cues from predators or predator products (Janssen et al. 1998; Pallini et al. 1998; Grostal and Dicke 1999; Venzon et al. 2000; Stumpner and von Helversen 2001; Agarwala et al. 2003; Nomikou et al. 2003; de Bruijn et al. 2006; Lohrey et al. 2009). The ability of prey to distinguish high-risk predators from low-risk or harmless predators has important implications for the prey's reproductive success. Failing to recognize a predator is likely to increase the probability of capture during an encounter, and defensive responses to nonpredators are likely to result in lost foraging and mating opportunities (Hirsch and Bolles 1980; Lima and Dill 1990; Chivers et al. 1996). Hence, it is important that prey accurately identify predator-related cues in order to assess the level of predation risk (Chivers et al. 1996).

In spider mites, the anti-predator responses described thus far mainly concern the avoidance of patches with high predation risk (Grostal and Dicke 1999; Pallini et al. 1999; Magalhães et al. 2002; Choh and Takabayashi 2007), but recently attention has also been given to predator-induced diapause (Kroon et al. 2008) and reduction of oviposition (Oku et al. 2004; Skaloudova et al. 2007; Choh et al. 2010). Spider mites are also hypothesized to reduce predation risk through the production of a dense web (Sabelis and Bakker 1992; Oku et al. 2003; Horita et al. 2004; Shimoda et al. 2009). Moreover, the web has been hypothesized to serve various other purposes, such as attachment to the leaf and protection against adverse climatic conditions (Gerson 1985). Indeed, by modifying their microhabitat, spider mites act as "ecosystem engineers" (Jones et al. 1997). Other organisms can also profit from the spider mite's web; thrips and predatory mites can also use it as protection against their predators (Pallini et al. 1998; Roda et al. 2000; Venzon et al. 2000).

Little is known of the within-species variation in the production of web. Because the silk of the web consists of protein (Hazan et al. 1975), the production must be costly, and it can therefore be expected that mites will fine-tune web construction to variation in the environment. Indeed, natural populations of Tetranychus urticae harbour genetic variation in web production (Tien et al. 2009). It is also conceivable that web production shows phenotypic variation, for example, spider mites may start producing denser web when perceiving the presence of predators. In this article, we investigate this, using the red spider mite, Tetranychus evansi Baker \& Pritchard, and the predatory mite, Phytoseiulus longipes Evans.

Compared to other Tetranychus species, the red spider mite is a highly destructive crop pest, with high rates of population increase over a wide temperature range (Bonato 1999). It is one of the major pests of solanaceous plants, especially tomato (Ferragut and Escudero 
1999) and has been recorded in South and North America, Africa, Spain, Portugal, Greece and Taiwan (Ramalho and Flechtmann 1979; Blair 1989; Ferragut and Escudero 1999; Bolland and Vala 2000; Ho et al. 2004; Tsagkarakou et al. 2007). A striking characteristic of $T$. evansi is its high production of web compared with other Tetranychus species (Ferragut and Escudero 1999).

Recently, $P$. longipes was found associated with $T$. evansi in South Brazil (Furtado et al. 2006). It shows potential as a biological control agent (Furtado et al. 2007). However, for a successful biological control program, it is important to understand the interactions between predator and prey within the overall food web context in agricultural crops (Janssen et al. 1998). The non-lethal effects of predators on prey might be an important component of predator-prey interactions in food webs because they can be as large as lethal effects (Schmitz 1998).

Here, the objective is to understand how the web of $T$. evansi mediates predator-prey interactions. To this end, we tested whether the spider mites recognize cues of predation and whether these cues induce them to produce more web or to change other aspects of their behaviour. Increased web production might impede effective control of the spider mites by predators. We subsequently studied the effect of these changes in behaviour of the red spider mite on predation of eggs by the predatory mite.

\section{Materials and methods}

Tomato plants (Solanum lycopersicum var. Santa Clara I-5300) were weekly sown in a commercial plant substrate (Bioplant ${ }^{\circledR}$, Bioplant Misturadora Agrícola LTDA, Nova Ponte, MG) in a polystyrene tray $(8 \times 16$ cells $)$ in a greenhouse. Trays with seedlings were kept inside a cage with a fine mesh to avoid contamination with herbivores. Upon reaching 20 days of age, we transplanted the seedlings to pots $(5 \mathrm{~L})$ with a mixture of soil, bovine manure and mineral fertilizer (NPK 04-14-08) in larger mesh-covered cages in a greenhouse.

A population of T. evansi was obtained in 2002 from a natural infestation of tomato plants in a greenhouse in Viçosa, Minas Gerais, Brazil. The spider mites were reared on tomato leaves with their petiole inserted in a PVC tube filled with water to prevent desiccation of the leaves. Tubes with infested leaves were kept in PVC trays filled with detergent and water $(1: 25, \mathrm{v} / \mathrm{v})$, which served to prevent mite escapes and invasion of mites and other non-flying arthropods. The mass culture was maintained in a room $\left(25 \pm 3{ }^{\circ} \mathrm{C}\right.$, 70-90\% relative humidity) with controlled photoperiod (12:12 L:D).

The laboratory culture of the predatory mite $P$. longipes was started with individuals that were kindly sent by Dr Gilberto de Moraes from the University of São Paulo, Brazil. Colonies were maintained in a climate cabinet $\left(28 \pm 2{ }^{\circ} \mathrm{C}, 80 \pm 10 \%\right.$ relative humidity), fed daily with $T$. evansi on tomato leaves from the spider mite culture. All experiments were carried out in a climate cabinet $\left(25 \pm 1^{\circ} \mathrm{C}, 80 \pm 10 \%\right.$ relative humidity $)$.

Effect of predator cues on oviposition and web production

Small discs $(\varnothing=1.2 \mathrm{~cm})$ were cut from tomato leaves and were exposed to predators by releasing 10 individuals of $P$. longipes per disc. Control leaf discs were cut at the same time from the same plant to exclude effects of plant quality and did not receive predators. Ten leaf discs were arranged in a regular pattern on wet cotton wool in a Petri dish. After $24 \mathrm{~h}$, we gently removed all predatory mites and their eggs from the discs, leaving only 
other cues from the predators. A fine brush was used for manipulations of the mites, which was cleaned in water after removing the predators. Using a thin brush, one female of a cohort of T. evansi, aged 3-5 days since turning adult, was placed on each disc. After $48 \mathrm{~h}$ we measured oviposition and web production. We counted the number of prey eggs both suspended in the web and on the leaf surface under the web.

Subsequently, web density was quantified with a technique adapted from Sabelis (1981). We collected a small sample of red clay soil (oxisol) that was dried in an incubator. The dried soil was subsequently run through a series of sieves and the fraction of particles with a diameter of $0.177 \mathrm{~mm}$ was stored for further use. To quantify the web density, we sprinkled soil particles over a leaf disc with web, using a fine brush. The red colour of the soil particles contrasts well with the green leaf tissue. The particles were light enough to remain attached to the sticky spider mite silk. Some particles would adhere to the silk, whereas others would drop through the web of silken strands and land on the surface of the leaf disc. With increasing web density, more particles remain suspended in the web (R. Sarmento and A. Janssen, personal observation). We therefore defined web density as the percentage of particles that was found suspended in the web. Particles were counted and their position (in the web or on the leaf) scored using a stereo microscope.

The experiment was done in two blocks, one with 30 and one with 20 females of control and treatment each. Data from spider mites that had died during the experiment were discarded (26\% of all mites). This resulted in 22 and 17 replicates for clean leaf discs and 23 and 12 replicates for leaf discs with predator cues for the two blocks, respectively. There was no difference in this mortality due to treatment (Generalized Linear Model with binomial error distribution: deviance $=0.834, d f=1, P=0.361$ ).

Effect of web and position of prey eggs on their survival

As will be shown in the Results section, spider mites laid more eggs suspended in the web when exposed to predator cues than in the absence of such cues. This experiment served to study predation of eggs being positioned in the web or on the leaf surface. We treated leaf discs with predators prior to allowing spider mites to produce web and oviposit to obtain leaf discs with spider mite eggs suspended in the web. In an attempt to increase the proportion of eggs suspended in the web, we used larger leaf discs $(\varnothing=1.7 \mathrm{~cm})$, more predators and a longer exposure of discs to predators $(48 \mathrm{~h})$ than in the previous experiment. Thirty leaf discs were first exposed to 15 adult female predators. Because the discs did not contain food for the predators, many of them escaped from the disc. We therefore added 15 more individuals on the second day. This was to ensure that leaf discs would contain ample amounts of cues of predatory mites. As a control, discs without predator cues were used (44 replicates). After 2 days, the predators were removed as above, and the discs without (control) or with predator cues were infested with 15 females of $T$. evansi for 3 days. As in the previous experiment, the effect of predator cues on oviposition behaviour of the spider mite was assessed by counting the number of prey eggs on the leaf surface and suspended in the web. Web density was not quantified because of its possible interference with the behaviour of the predators that were subsequently released on the leaf discs.

On all leaf discs, the adult spider mites were killed with a fine insect needle, but the eggs and web were left intact. The web was subsequently removed from 20 of the 44 control discs without predator cues. The removal of the web will have resulted in the removal of a few eggs that were laid suspended in the web, but in the absence of predator cues, the large majority of eggs was positioned on the leaf surface (see Results section). The web on the discs with predator cues was left intact. This resulted in three treatments: (1) leaf discs with 
prey eggs but without web and without predator cues (controls without web, $N=20$ ), (2) discs with prey eggs, predominantly on the leaf surface, and with web but without predator cues (controls with web, $N=24$ ), and (3) discs with predator cues and with prey eggs both on the leaf surface and suspended in the web (predator treatment, $N=30$ ). A young adult, mated female predatory mite was released on each disc and the remaining prey eggs and the eggs laid by the predator on both leaf surface and suspended in the web were counted after $24 \mathrm{~h}$. The experiment was done in three blocks through time: once with 12 replicates of each treatment and control; once with six replicates of the predator treatment and the control with web and five of the control without web; and a third time with 12 replicates of the predator treatment, six of the control with web and three of the control without web.

\section{Statistical analysis}

We observed that web density and oviposition varied considerably through time (F. Lemos and R. Sarmento, personal observation). Because experiments were done in blocks through time, with each treatment in each block, we used linear mixed effects models (LMER, library lme4, R Development Core Team 2006), with block as random variable. For quantification of web production, we used the numbers of soil particles on the disc surface and in the web as dependent variable and a quasibinomial error distribution to correct for overdispersion (Crawley 2007). Total numbers of spider mite eggs on discs with cues of predators and clean discs were compared with a LMER with a quasi-Poisson error distribution to correct for overdispersion. The distribution of data on eggs of T. evansi on the leaf surface or suspended in the web was strongly non-normal due to zero inflation, even after transformations; we therefore used the more conservative nonparametric Wilcoxon rank sum test to compare the fraction of eggs suspended in the web. Predation rates and oviposition rates of $P$. longipes were also compared with LMER with quasi-binomial and quasi-Poisson errors respectively. Models were simplified by removing non-significant interaction terms and factors, until a minimal adequate model was obtained (Crawley 2007). All the analyses were done using the statistical software R 2.6.2 (R-DevelopmentCore-Team 2006) and the models were checked for heteroscedasticity and normality of errors according to Crawley (2007).

\section{Results}

Effect of predator cues on oviposition and web production

Predator cues did not significantly affect web production by $T$. evansi (LMER: $\left.\mathrm{Chi}^{2}=1.82, d f=1, P=0.18\right)$. Overall, $24.2 \pm 1.34 \%$ of the particles was found suspended in the web on leaf discs without predator cues and $26.1 \pm 1.50 \%$ was in the web in the presence of predator cues.

The oviposition of red spider mite females was not significantly affected by the presence of predator cues (Fig. 1, LMER: $\mathrm{Chi}^{2}=2.66, d f=1, P=0.10$ ). However, the spider mites did lay more eggs suspended in the web on discs with predator cues (Fig. 1, Wilcoxon rank-sum test: $W=214.5, P<0.0001)$. In the absence of predator cues, all eggs were laid on the leaf disc surface, whereas $29.2 \pm 5.50 \%$ of the eggs were found suspended in the web in the presence of predator cues. Because there were no predators but only predator cues present when the spider mites were allowed to oviposit and construct web, we conclude that predator cues changed the oviposition behaviour of T. evansi. 


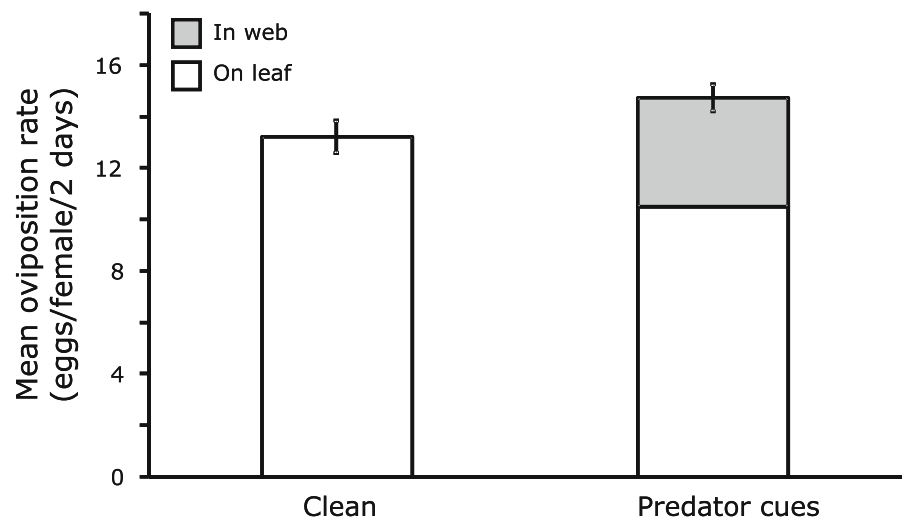

Fig. 1 Mean oviposition rates of single Tetranychus evansi females during 2 days on leaf discs that were either clean or contained cues of the predatory mite Phytoseiulus longipes. White parts of the bars show the number of eggs on the leaf surface, grey parts show the eggs that were suspended in the web. Error bars show the SEM of the mean total number of eggs (on the leaf surface plus in the web)

\section{Effect of web and position of prey eggs on predation}

To assess the effects of the changed oviposition behaviour of T. evansi as described above, we compared egg predation on discs with all eggs on the disc surface with that on discs with a proportion of the eggs suspended in the web. In order to obtain leaf discs with suspended eggs, we repeated the above experiment with slightly larger leaf discs and more predator cues. Again, we found more eggs suspended in the web when predator cues were present than on clean leaf discs (Fig. 2, Wilcoxon rank-sum test: $W=19, P<0.0001$ ). On average, $36.1 \pm 4.86 \%$ of the eggs were laid in the web on discs with predator cues while $0.71 \pm 0.27 \%$ was found in the web on clean discs. We now found significantly lower

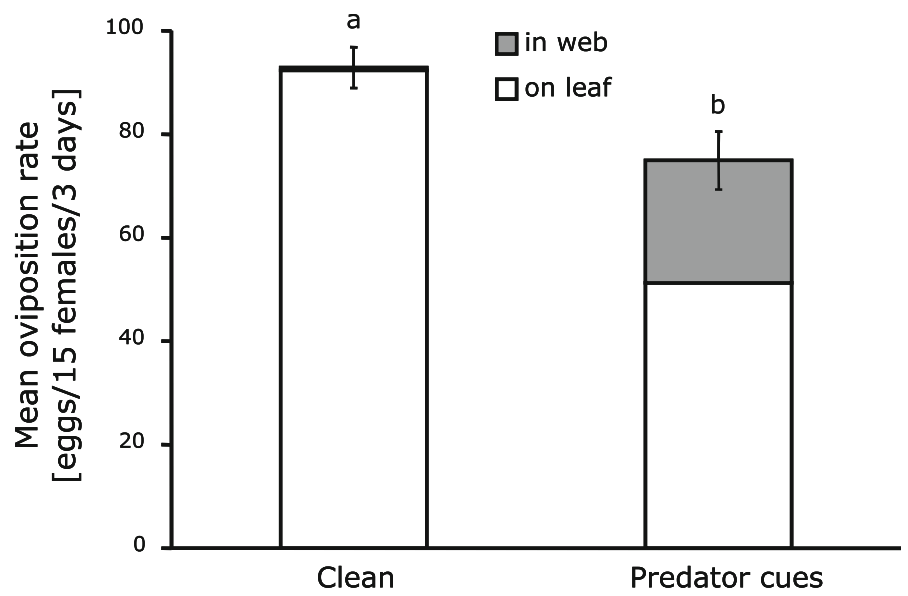

Fig. 2 Mean oviposition rates of groups of 15 adult females of Tetranychus evansi either on clean tomato leaf discs or on discs with cues of the predatory mite Phytoseiulus longipes. White parts of the bars show the number of eggs on the leaf surface, grey parts show the eggs that were suspended in the web. Error bars show the SEM of the mean total number of eggs (on the leaf surface plus in the web). Different letters above the vertical bars denote a significant difference in total numbers of eggs between the treatments $(P<0.05)$ 


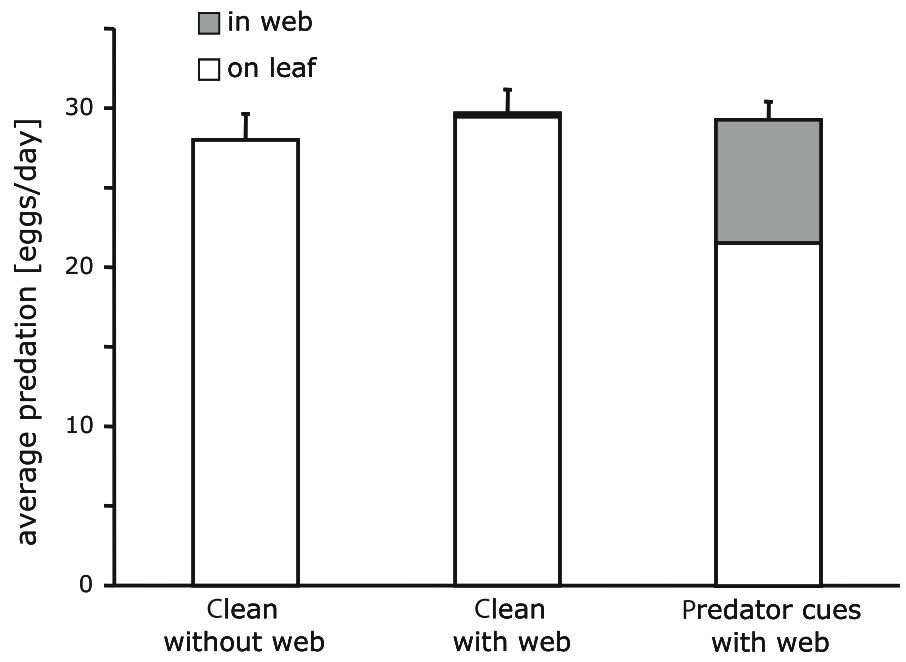

Fig. 3 Mean predation rate by Phytoseiulus longipes on eggs of the spider mite Tetranychus evansi in the presence of predator cues and web produced by the spider mite or in the absence of predator cues (clean) with or without web. White bars show predation of eggs from the leaf surface, grey bars predation of eggs that were suspended in the web. Error bars indicate standard errors of the mean total predation (in web plus on leaf)

oviposition rates in the presence of predator cues (Fig. 2, LMER: $\mathrm{Chi}^{2}=45.5, d f=1$, $P<0.0001)$.

Predation by $P$. longipes was not affected by the presence of web or cues of conspecifics (Fig. 3, LMER: $\mathrm{Chi}^{2}=2.06, d f=2, P=0.36$ ), showing that the lower density of prey eggs in the treatment with predator cues (Fig. 2) did not affect predation. We subsequently analyzed the predation rate of eggs of $T$. evansi on the leaf surface and in the web in the treatment with predator cues only (the other two treatments had too few eggs in the web). The overall percentage of suspended eggs that was killed was $32.8 \pm 4.3 \%$, whereas $50.2 \pm 3.4 \%$ of all eggs on the leaf surface were consumed, and this difference was highly significant (LMER: $\mathrm{Chi}^{2}=35.3, d f=1, P<0.0001$ ). Hence, depositing eggs suspended in the web, away from the leaf surface, reduces the risk of predation.

\section{Discussion}

We found no effect of the presence of predator cues on the density of web produced by females of $T$. evansi. Using the same method of estimating web density, preliminary experiments showed that the production of web by this spider mite is flexible, depending on the ecological setting (R. A. Sarmento, personal observation). However, spider mite web in general does not protect against all species of predator. For example, the predatory mite Phytoseiulus persimilis can cope with the silken web produced by its prey, the twospotted spider mite T. urticae. Adaptations of predatory mites to web of their prey are hypothesized to be linked to the morphology and the pattern of the mid-dorsal and lateral setae of the predators (Sabelis and Bakker 1992), and to their ability to cut silken strands of the web (Shimoda et al. 2009). Because both predation rates and oviposition rates of $P$. longipes were not reduced by the web of $T$. evansi, we suggest that this predator has 
evolved to counter this defence of its prey, and is a potential candidate for biological control of this upcoming pest. This is in agreement with observations by Furtado et al. (2006), who state that the movement of P. longipes was not impeded on tomato leaves covered with the web of $T$. evansi. An increase in web production would perhaps not result in decreased predation by $P$. longipes. It is still possible, therefore, that cues of predator species that are hindered by the web would induce an increase in web production. This requires further research.

Predator cues did elicit another behavioural response in the prey, i.e. the spider mites oviposited more frequently on the silken strands of the web, away from the leaf surface. This indicates that they perceived the predator cues. The apparent change in oviposition behaviour resulted in a lower risk of predation on these eggs. Hence, T. evansi preferentially oviposits on the leaf surface, and alters this behaviour only when perceiving predator cues. This can be understood given the life style of spider mites: they feed on the leaf parenchyma (Helle and Sabelis 1985), and usually oviposit on the leaf surface. Ovipositing away from their food source would probably involve costs in terms of time and energy spent by the females in moving from the leaf surface into the web. Moreover, larvae that emerge suspended in the web need to find the leaf surface. All these costs may go at the expense of fitness-related components such as egg production, development and survival. Oku et al. (2003) found a similar use of web by spider mites; quiescent stages of the spider mite T. kanzawai had a reduced predation risk on top of their web than under it, but had a lower probability of being guarded by males, and therefore possibly a lower probability of mating.

We found lower oviposition of the spider mites on leaf discs with predator cues in the experiment on the effect of web and position of prey eggs on predation (Fig. 2), but not in the experiment on the effect of predator cues (Fig. 1). This may be due to the higher concentration of predator cues in the second experiment and the longer period over which oviposition was measured ( 3 days vs. 2 days in the first experiment). The reduced oviposition is another indirect effect of predators on the prey (Oku et al. 2004), and may result in lower population growth rates, thus further contributing to the suppression of populations of this pest.

It is unclear why the spider mites laid only around $30 \%$ of their eggs in the web and not all of them. Perhaps the concentration of predator cues or the physical presence of a predator determines the extent of the behavioural change. Alternatively, the effect of suspending eggs in the web may be frequency dependent; possibly, the predators would concentrate their searching in the web if all the eggs were suspended. The eggs that were laid on the leaf surface may act to distract the attention of the predator, thereby rendering the suspended eggs relatively safe. If so, there should be an optimum oviposition strategy where spider mites balance predation risk of eggs on and away from the leaf surface against the costs of laying eggs suspended in the web.

The effects of predator presence or predator cues on behaviour of prey are well documented for a diverse array of vertebrate and invertebrate prey (Lima and Dill 1990; Lima and Bednekoff 1999). Such adaptive responses include morphological changes, life history shifts and behavioural responses (Havel 1987; Lima and Dill 1990; Kats and Dill 1998; Tollrian and Harvell 1999); these last two being reported more frequently. It is known that spider mites can use chemical cues to recognize and avoid patches with predation risk (Grostal and Dicke 1999; Pallini et al. 1999). Here we show that such cues can also induce another type of antipredator behaviour, i.e. a change in the site of oviposition within patches. 
Acknowledgments The comments of two anonymous reviewers resulted in substantial improvement of this ms. We thank CNPq-Brazil for financial support. RAS received a scholarship from WOTRO-NWO (Netherlands Foundation for the Advancement of Tropical Research, project W82-281), AP received a scholarship from CNPq, Brazil, AJ was supported by FAPEMIG (Pesquisador Visitante).

Open Access This article is distributed under the terms of the Creative Commons Attribution Noncommercial License which permits any noncommercial use, distribution, and reproduction in any medium, provided the original author(s) and source are credited.

\section{References}

Agarwala BK, Bardhanroy P, Yasuda H, Takizawa T (2003) Effects of conspecific and heterospecific competitors on feeding and oviposition of a predatory ladybird: a laboratory study. Entomologia Experimentalis Et Applicata 106:219-226

Blair BW (1989) Laboratory screening of acaricides against Tetranychus evansi Baker and Pritchard. Crop Prot 8:212-216

Bolland H, Vala F (2000) First record of the sipder mite Tetranychus evansi (Acari: Tetranychidae) from Portugal. Entomologische Berichten 60:180

Bonato O (1999) The effect of temperature on life history parameters of Tetranychus evansi (Acari: Tetranychidae). Exp Appl Acarol 23:11-19

Chivers DP, Wisenden BD, Smith RJF (1996) Damselfly larvae learn to recognize predators from chemical cues in the predator's diet. Anim Behav 52:315-320

Chivers DP, Zhao XX, Brown GE, Marchant TA, Ferrari MCO (2008) Predator-induced changes in morphology of a prey fish: the effects of food level and temporal frequency of predation risk. Evol Ecol 22:561-574

Choh Y, Takabayashi J (2007) Predator avoidance in phytophagous mites: response to present danger depends on alternative host quality. Oecologia 151:262-267

Choh Y, Uefune M, Takabayashi J (2010) Predation-related odours reduce oviposition in a herbivorous mite. Exp Appl Acarol 50:1-8

Crawley MJ (2007) The R book. John Wiley, Chichester

de Bruijn PJA, Egas M, Janssen A, Sabelis MW (2006) Pheromone-induced priming of a defensive response in Western flower thrips. J Chem Ecol 32:1599-1603

Ferragut F, Escudero A (1999) Tetranychus evansi Baker \& Pritchard (Acari, Tetranychidae), uma nueava araña roja en los cultivos hortícolas españoles. Bol San Veg Plagas 25:157-164

Furtado IP, de Moraes GJ, Kreiter S, Knapp M (2006) Search for effective natural enemies of Tetranychus evansi in south and southeast Brazil. Exp Appl Acarol 40:157-174

Furtado IP, de Moraes GJ, Kreiter S, Tixier MS, Knapp M (2007) Potential of a Brazilian population of the predatory mite Phytoseiulus longipes as a biological control agent of Tetranychus evansi (Acari: Phytoseiidae: Tetranychidae). Biol Control 42:139-147

Gerson U (1985) Webbing. In: Helle W, Sabelis MW (eds) Spider mites: their biology, natural enemies and control. Elsevier, Amsterdam, pp 223-232

Grostal P, Dicke M (1999) Direct and indirect cues of predation risk influence behavior and reproduction of prey: a case for acarine interactions. Behav Ecol 10:422-427

Havel J (1987) Predator-induced defences: a review. In: Kerfoot CW, Sih A (eds) Predation: direct and indirect impacts on aquatic communities. University Press of New England, Hanover

Hazan A, Gertler A, Tahori AS, Gerson U (1975) Spider mite webbing-III. Solubilization and amino acid composition of the silk protein. Comp Biochem Physiol B: Biochem Mol Biol 51:457-462

Helle W, Sabelis MW (1985) Spider mites: their biology, natural enemies and control. Elsevier, Amsterdam

Hirsch S, Bolles R (1980) On the ability of prey to recognize predators. Zeitschrift fur Tierpsychologie 54:71-84

Ho C, Wang S, Chien Y (2004) Field observations on two newly recorded spider mites in Taiwan. Plant Protect Bull 47:391-402

Horita M, Chittenden AR, Sato Y, Saito Y (2004) Function of the web box as an anti-predator barrier in the spider mite, Schizotetranychus recki. J Ethol 22:105-108

Janssen A, Pallini A, Venzon M, Sabelis MW (1998) Behaviour and indirect interactions in food webs of plant- inhabiting arthropods. Exp Appl Acarol 22:497-521

Jones CG, Lawton JH, Shachak M (1997) Positive and negative effects of organisms as physical ecosystem engineers. Ecology 78:1946-1957 
Kats LB, Dill LM (1998) The scent of death: chemosensory assessment of predation risk by prey animals. Ecoscience 5:361-394

Kroon A, Veenendaal RL, Bruin J, Egas M, Sabelis MW (2008) “Sleeping with the enemy"-predatorinduced diapause in a mite. Naturwissenschaften 95:1195-1198

Lima SL (1998) Nonlethal effects in the ecology of predator-prey interactions-what are the ecological effects of anti-predator decision-making? Bioscience 48:25-34

Lima SL, Bednekoff PA (1999) Temporal variation in danger drives antipredator behavior: the predation risk allocation hypothesis. Am Nat 153:649-659

Lima SL, Dill LM (1990) Behavioral decisions made under the risk of predation-a review and prospectus. Can J Zool 68:619-640

Lohrey AK, Clark DL, Gordon SD, Uetz GW (2009) Antipredator responses of wolf spiders (Araneae: Lycosidae) to sensory cues representing an avian predator. Anim Behav 77:813-821

Magalhães S, Janssen A, Hanna R, Sabelis MW (2002) Flexible antipredator behaviour in herbivorous mites through vertical migration in a plant. Oecologia 132:143-149

Montserrat M, Bas C, Magalhaes S, Sabelis MW, de Roos AM, Janssen A (2007) Predators induce egg retention in prey. Oecologia 150:699-705

Nomikou M, Janssen A, Sabelis MW (2003) Herbivore host plant selection: whitefly learns to avoid host plants that harbour predators of her offspring. Oecologia 136:484-488

Oku K, Yano S, Takafuji A (2003) Spider mite's use of a refuge during the quiescent stage in the presence of a predator. Entomol Exp Appl 108:71-74

Oku K, Yano S, Takafuji A (2004) Nonlethal indirect effects of a native predatory mite, Amblyseius womersleyi Schicha (Acari: Phytoseiidae), on the phytophagous mite Tetranychus kanzawai Kishida (Acari: Tetranychidae). J Ethol 22:109-112

Pallini A, Janssen A, Sabelis MW (1998) Predators induce interspecific herbivore competition for food in refuge space. Ecol Lett 1:171-177

Pallini A, Janssen A, Sabelis MW (1999) Spider mites avoid plants with predators. Exp Appl Acarol 23:803-815

Ramalho F, Flechtmann C (1979) Níveis de infestação de Tetranychus evansi Baker e Pritchard, 1960 em diferentes fases de desenvolvimento de tomateiro. Rev Agricult 54:51-56

R Development Core Team (2006) R Foundation for Statistical Computing. Vienna, Austria

Roda A, Nyrop J, Dicke M, English-Loeb G (2000) Trichomes and spider-mite webbing protect predatory mite eggs from intraguild predation. Oecologia 125:428-435

Sabelis MW (1981) Biological control of two-spotted spider mites using phytoseiid predators. Part I. Pudoc, Wageningen

Sabelis MW, Bakker FM (1992) How predatory mites cope with the web of their Tetranychid prey-a functional view on dorsal chaetotaxy in the Phytoseiidae. Exp Appl Acarol 16:203-225

Schmitz OJ (1998) Direct and indirect effects of predation and predation risk in old-field interaction webs. Am Nat 151:327-342

Shimoda T, Kishimoto H, Takabayashi J, Amano H, Dicke M (2009) Comparison of thread-cutting behavior in three specialist predatory mites to cope with complex webs of Tetranychus spider mites. Exp Appl Acarol 47:111-120

Sih A (1980) Optimal behavior: can foragers balance two conflicting needs? Science 210:1041-1043

Sih A (1982) Foraging strategies and the avoidance of predation by an aquatic insect, Notonecta hoffmanni. Ecology 63:786-796

Skaloudova B, Zemek R, Krivan V (2007) The effect of predation risk on an acarine system. Anim Behav $74: 813-821$

Stumpner A, von Helversen D (2001) Evolution and function of auditory systems in insects. Naturwissenschaften 88:159-170

Tien NSH, Sabelis MW, Egas M (2009) The heritability of defense and life-history traits in the two-spotted spider mite. Evol Ecol Res 11:1271-1281

Tollrian R, Harvell CD (1999) The evolution of inducible defenses: current ideas. In: Tollrian R, Harvell CD (eds) The ecology of inducible defenses. Princeton University Press, Princeton, pp 306-321

Tsagkarakou A, Cros-Arteil S, Navajas M (2007) First record of the invasive mite Tetranychus evansi in Greece. Phytoparasitica 35:519-522

Venzon M, Janssen A, Pallini A, Sabelis MW (2000) Diet of a polyphagous arthropod predator affects refuge seeking of its thrips prey. Anim Behav 60:369-375 